\title{
ICE THICKNESS AND SEA DEPTH DERIVED FROM REFLECTION-SEISMIC MEASUREMENTS ON THE CENTRAL PART OF FILCHNER-RONNE ICE SHELF, ANTARCTICA
}

\author{
by
}

\author{
J. Determann, F. Thyssen and H. Engelhardt
}

(Forschungsstelle für physikalische Glaziologie der Westfälischen Wilhelms-Universität, Corrensstraße 24, D - 4400 Münster, Federal Republic of Germany)

\section{ABSTRACT}

In January 1986, reflection-seismic measurements were made in the central part of Filchner-Ronne Ice Shelf, north of Henry and Korff ice rises, by a German oversnow traverse. With the help of a newly developed "ice streamer", two people were able to obtain seismic records nearly every $5 \mathrm{~km}$ over a distance of $150 \mathrm{~km}$ within $3 \mathrm{~d}$. Processing of digitally recorded seismograms yielded profiles of ice thickness and sea depth. The ice thickness varies from 400 to $500 \mathrm{~m}$ and is in good agreement with the thickness of $465 \mathrm{~m}$ at a drill hole. The reflection-seismic results are comparable with those obtained from aerogeophysical measurements.

\section{INTRODUCTION}

There is some uncertainty about ice thickness over a broad area of Filchner-Ronne Ice Shelf (FRIS) down-stream of Henry Ice Rise, Korff Ice Rise and Doake Ice Rumples. Robin and others (1983) assumed ice thicknesses of less than $200 \mathrm{~m}$ in places, on the basis of electromagnetic reflection measurements (EMR or RES). A survey by Thyssen $(1985,1986)$ of a highly reflecting internal horizon at the margin of the ice shelf near the German Filchner Station, west of Berkner Island, raised questions about the earlier data. It appeared that RES measurements had widely detected an internal horizon and not the ice bottom.

Recent reflection-seismic studies by Herrod and Garrett (1986) failed to detect clear reflection signals from the ice bottom, probably due to a diffuse ice-water interface which was a result of freezing and caused a decrease in the reflection coefficient. As modern electromagnetic techniques are not able to penetrate the ice beneath the internal horizon, we started another test, using seismic methods. In January 1986 further seismic investigations were made at the center of FRIS. Figure 1 shows the reference numbers of a geodetic grid net and the locations where seismic measurements were carried out. An ice streamer proposed by Thyssen and towed by a tracked vehicle yielded a record of seismograms every 5 or $10 \mathrm{~km}$ without affecting the fast progress of the traverse group.

The processing of 25 seismograms along a $150 \mathrm{~km}$ profile from grid point 240 to grid point 335 has yielded details of the trends of the sea floor and ice bottom. They are supplemented by data derived from reflection seismograms which were recorded in 1984 near Filchner Station.

\section{FIELD WORK}

The seismograms were digitally recorded by means of a 12 channel amplifier system (Oyo McSeis 1500) with a dynamic range of $72 \mathrm{~dB}$. The cable had a total length of $234 \mathrm{~m}$ and contained 12 gimbal-mounted $4.5 \mathrm{cps}$ geophones spaced $18 \mathrm{~m}$ apart, and with a $36 \mathrm{~m}$ offset between the first

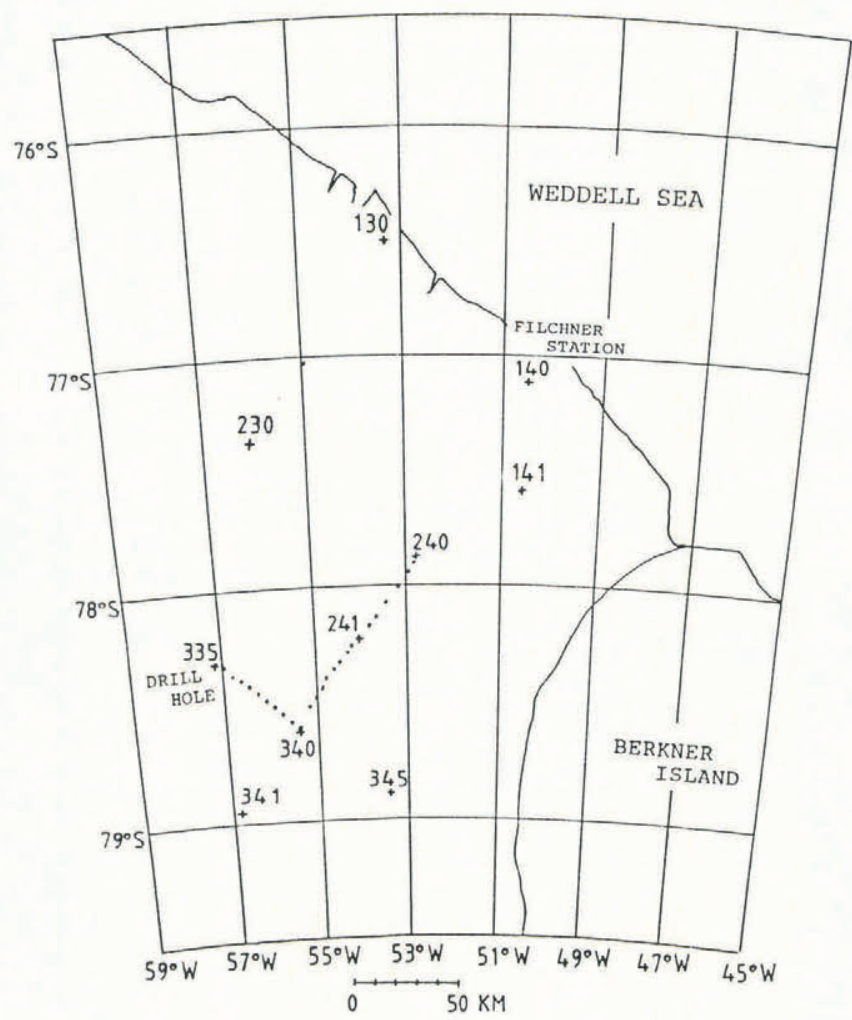

Fig. 1. The central part of Filchner-Ronne Ice Shelf west of Berkner Island. Sites where seismic records were obtained in 1986 are denoted by dots.

geophone and the shot. At every grid point where the traverse group had other glaciological work to do, additional seismograms were recorded with normally planted geophones. These, however, showed no significant improvement.

Because of the limitations of the recording system and after some test shots, the recording-time window was set to $1 \mathrm{~s}$ at a sample rate of $1 \mathrm{~ms}$. Explosive charges generally of $1 \mathrm{~kg}$ were used in hand-drilled bore holes of approximately $4.5 \mathrm{~m}$ depth. With the intention of obtaining multiple reflections from the ice bottom at several shot points, the charge was increased to $4.5 \mathrm{~kg}$ while using a delay time up to $500 \mathrm{~ms}$ for recording. In at least one case a multiple reflection was detected.

\section{PROCESSING}

Every seismic record was processed with standard routines like muting, gain control and filtering. Muting was carried out for at least the first $100 \mathrm{~ms}$ of records, in order 


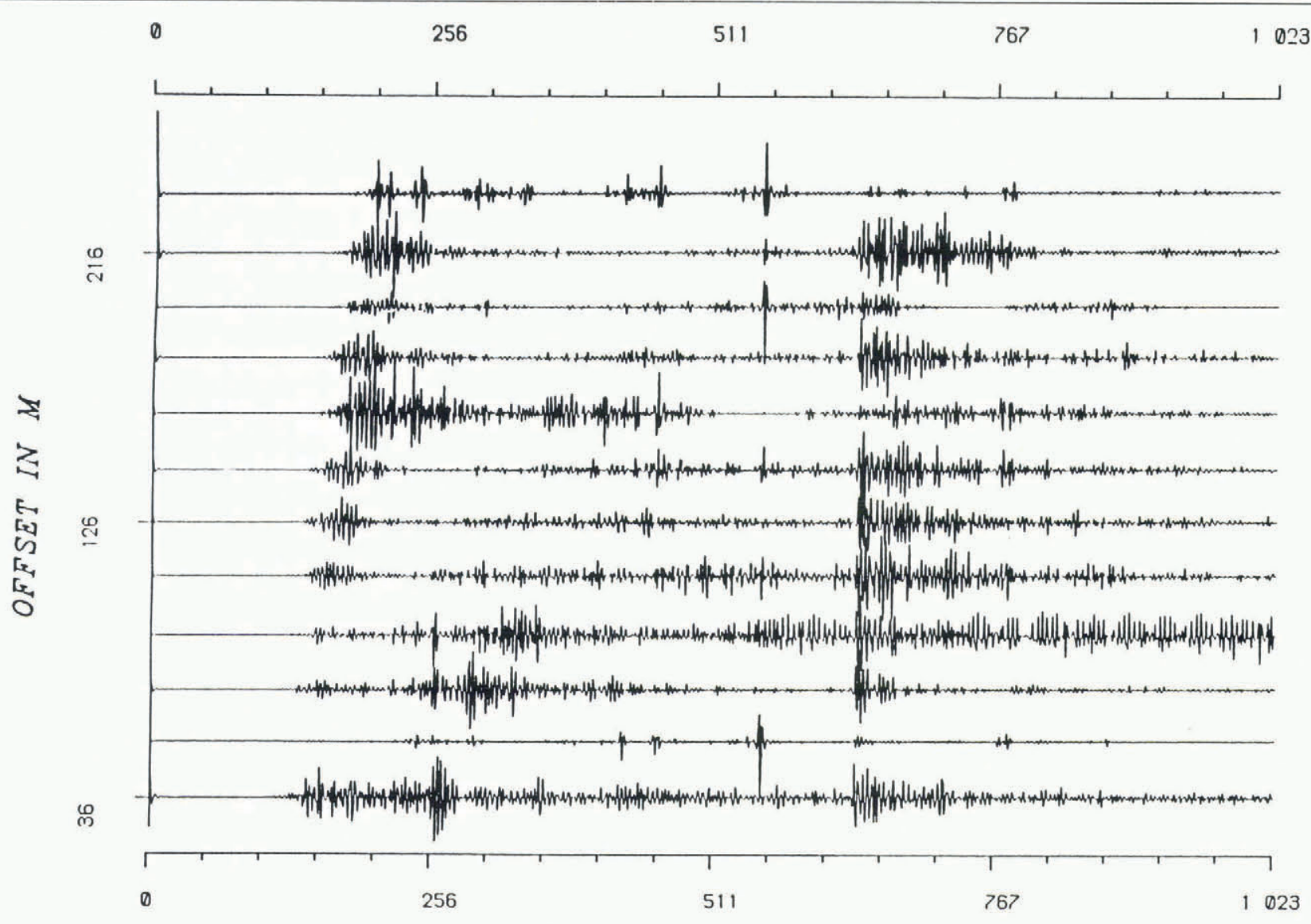

TRAVELTIME IN MS

Fig. 2. The processed record from shot point 16 at profile distance $50 \mathrm{~km}$, using $1 \mathrm{~kg}$, ice streamer and filter pass band $80-250 \mathrm{cps}$. The dominant reflection near $t_{0}=640$ ms must be related to the sea floor, whereas a seismic return from the ice bottom, estimated to lie between 200 and $300 \mathrm{~ms}$, is not visible. The event at $550 \mathrm{~ms}$ is electrostatic noise.

to reduce the gain of strong surface waves and refracted waves. Limiting the filter to an optimum pass band from 80 to $250 \mathrm{cps}$ led to further decreases in surface waves and electrostatic noise. Figure 2 shows a typical processed seismogram revealed from the ice streamer at profile $\mathrm{km} 50$ (GP 241). As a result of processing, the signal-to-noise ratio has increased but the record is still electrostatically disturbed (e.g. near $550 \mathrm{~ms}$ ). Strong reflections, in this case occurring at travel times of about $640 \mathrm{~ms}$, must be related to the return from the sea bottom. Clear evidence of ice-bottom reflections is still not visible.

Rough estimates of the maximum coherency stacking (MCS) velocity of longitudinal waves in the ice and of the known ice thickness of surrounding areas give rise to the assumption that the travel times of the ice-water reflections must be less than about $300 \mathrm{~ms}$. In order to show these returns, data had to be processed more extensively. On the assumption of almost horizontally layered media, without lateral inhomogeneities in the elastic constants, it is permissible to use a simplified form of stacking velocity analysis from a single seismogram (Garotta and Michon 1967).

The modified velocity analysis performs an amplitude stacking of all traces along computed reflection hyperbolas, belonging to different seismic MCS velocities and travel times at shot point $t_{0}$. Figure 3 shows the result of this velocity analysis as applied to the processed record in Figure 2, where every trace represents a stacking velocity and expresses the stacked amplitudes depending on $t_{0}$. Seismic reflectors are indicated by maxima in amplitude and appear at stacking velocities that give a good approximation of the root mean square (RMS) velocities in the case of horizontal layering. The error in this approximation is minimal when the geophone offset is sufficiently small in comparison with the depth of the seismic reflector, as is the case with the drag cable we used.
As the plot of the velocity analysis contains several maxima, further information is required in order to make a distinction between different horizons. A comparison with the unprocessed seismogram section identifies some of the maxima as arising from electrostatic noise. Furthermore, a knowledge of the MCS velocity enables us to obtain more evidence for seismic returns from the ice bottom. The interpretation of seismic short-refraction lines recorded in 1984 near Filchner Station yielded a velocity-depth profile of approximately the upper $100 \mathrm{~m}$ of the ice shelf. From this, an RMS velocity of around $3650 \mathrm{~m} / \mathrm{s}$ can be computed (for example) for an ice thickness of $400 \mathrm{~m}$, if we assume an ice velocity of $3815 \mathrm{~m} / \mathrm{s}$ for depths greater than $100 \mathrm{~m}$.

On the realistic assumption that lateral variations in velocity with depth on the inland seismic profile are sufficiently small, we have used a general value of $3650 \mathrm{~m} / \mathrm{s}$ for the observed area. Taking this RMS velocity, the return from an ice bottom at $500 \mathrm{~m}$ depth must appear at travel times of less than $300 \mathrm{~ms}$. A check on the time interval up to $t_{0}=300 \mathrm{~ms}$ and on stacking velocities at a range of $3650 \mathrm{~m} / \mathrm{s}$ yielded a number of maximum-amplitude events which may be related to an ice-bottom reflection. In order to reduce the number of events which are not real or which have arisen from noise, and to obtain a clearer view of the trend of the ice-bottom reflector, the contents of 24 velocity analyses were combined in one plot. This was done by extracting from each velocity analysis the trace belonging to the chosen RMS velocity and plotting it against the profile distance.

The result is shown in Figure 4, and yields further evidence for the existence of an ice-bottom reflector. Obviously the quality of any correlation of reflecting events depends on the distance of shot points. The best correlation is achieved by short-interval measurements where the spacing of shot points is only $5 \mathrm{~km}$, as in the profile section between 50 and $100 \mathrm{~km}$. Over the last five traces 


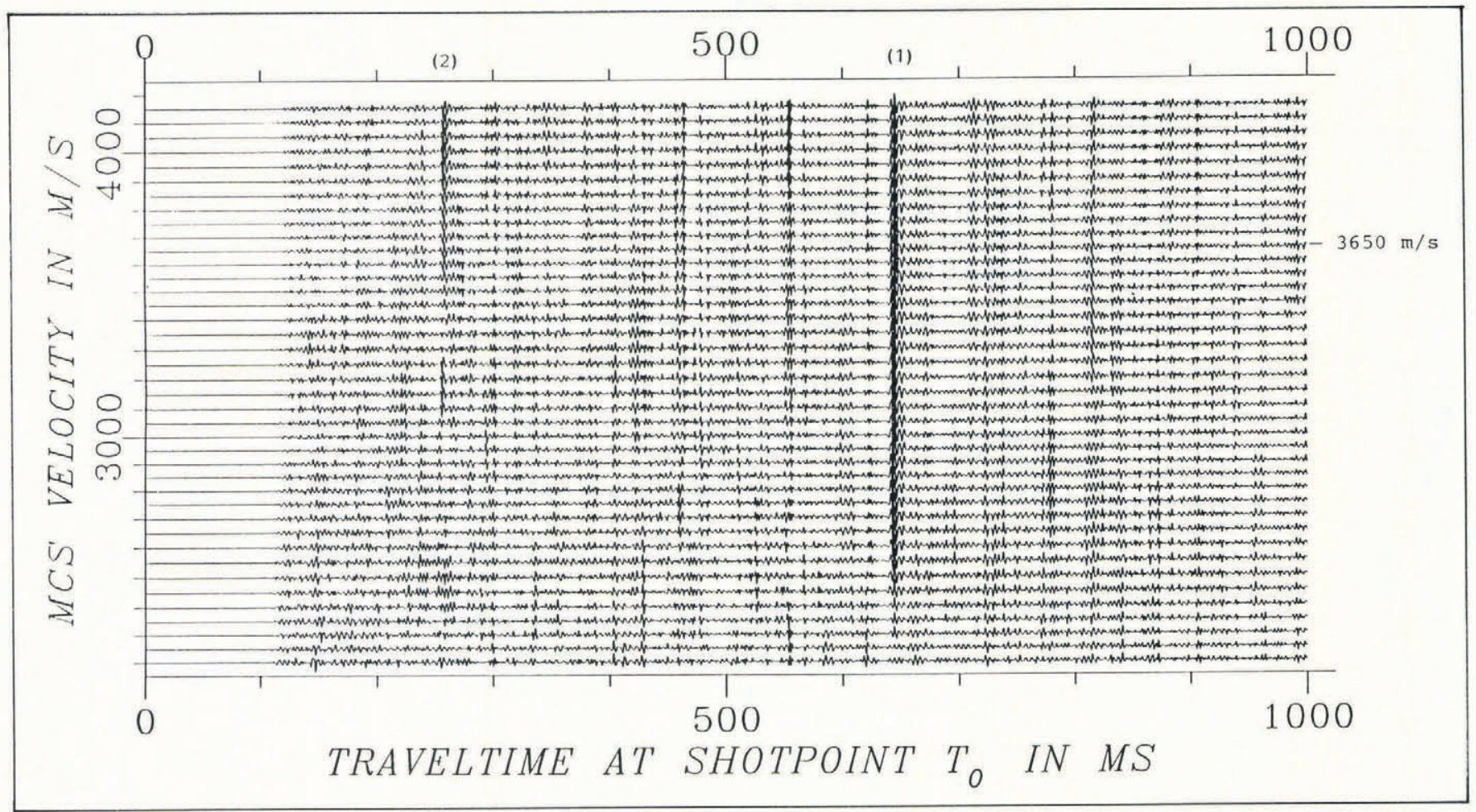

Fig. 3. Velocity analysis of the processed seismic record shown in Figure 2. The maximum at $\mathrm{t}_{0}=640 \mathrm{~ms}$ (1) corresponds to the reflection from the sea bottom. The assumed ice-bottom reflection is at $\mathrm{t}_{0}=270 \mathrm{~ms}(2)$.

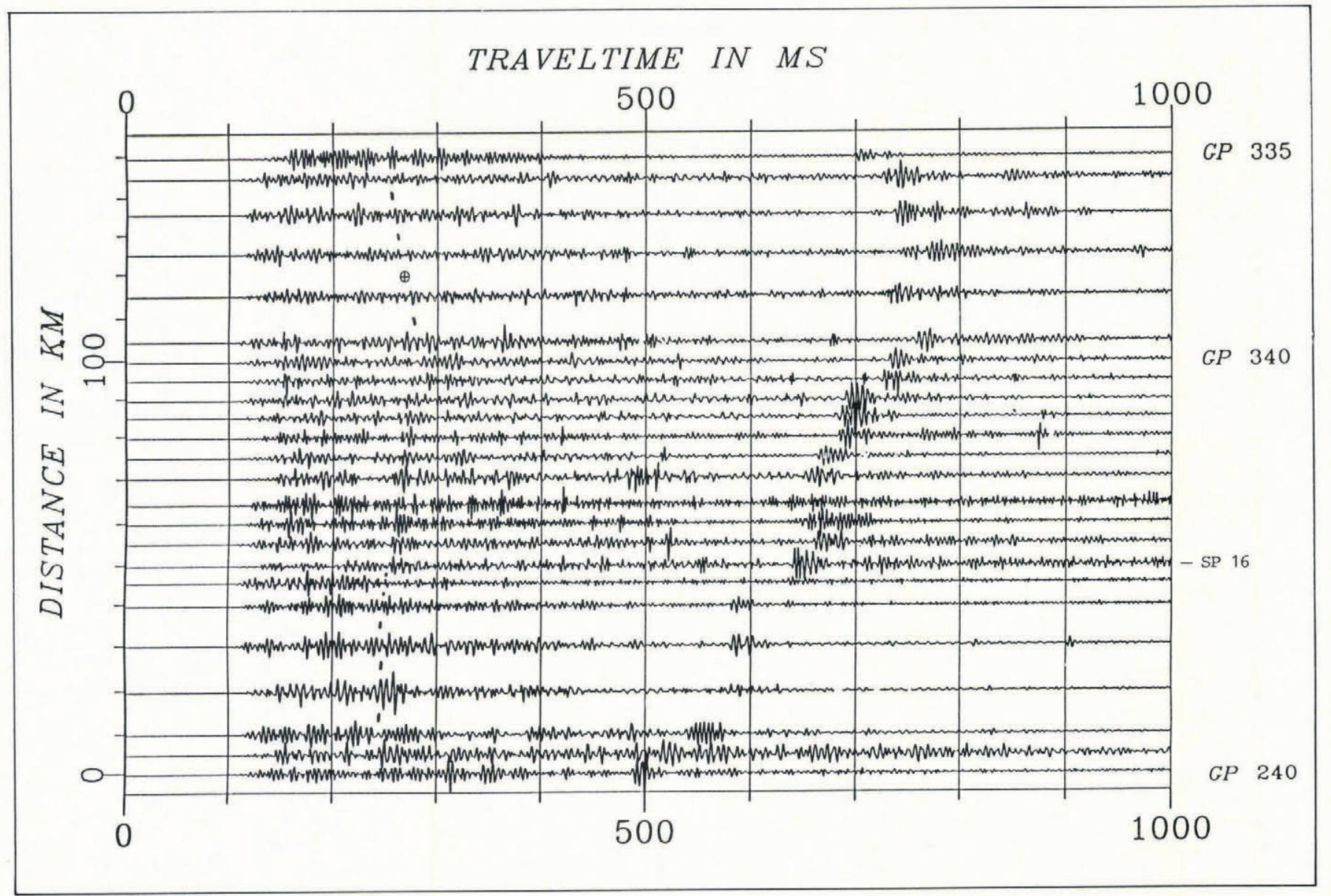

Fig. 4. A section of data after final processing, showing the distance of shot points with respect to grid point 240 versus travel time. Every trace is derived from the velocity analysis of a single record. The structure marked "- -" shows the trend of the ice-bottom reflection. In one case (symbol $\oplus$ ) the travel time is deduced from multiple reflections. The sea bottom appears at travel times greater than $500 \mathrm{~ms}$. A return from the internal horizon is not visible. 
Determann and others: Reflection-seismic measurements on the central part of Filchner-Ronne Ice Shelf

TABLE I. ICE AND SEA-BOTTOM DATA REVEALED FROM REFLECTION-SEISMIC MEASUREMENTS (sea bottom at the ice front from Kohnen (1982))

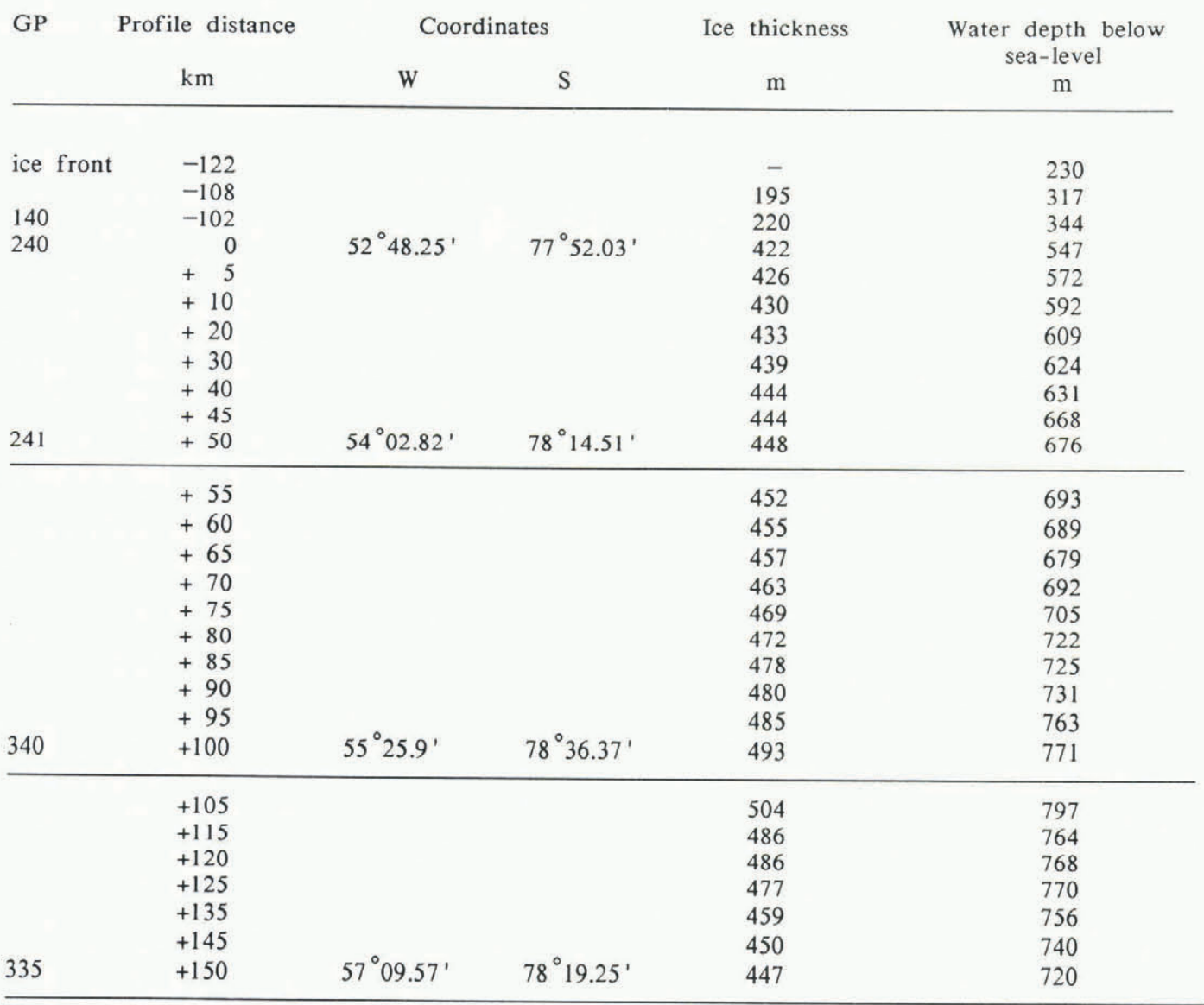

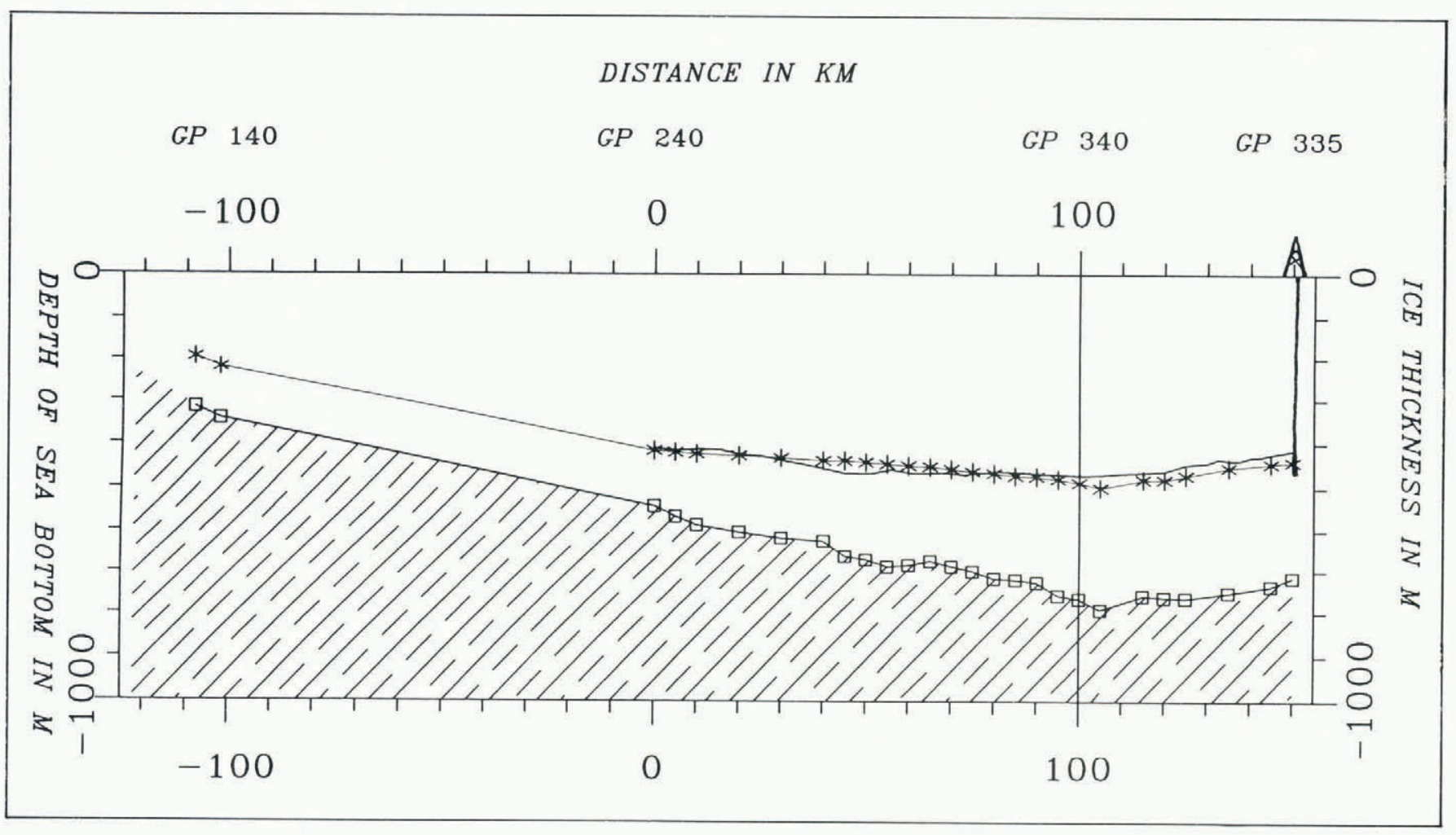

Fig. 5. Ice and sea-bottom profiles on a cross-section of Filchner-Ronne Ice Shelf extending inland from the ice front. Ice thicknesses from seismic measurements (medium line, stars), ice thicknesses from isostasy (heavy line) from Thyssen (1988, this volume), $465 \mathrm{~m}$ drill hole at grid point 335 from Engelhardt and Determann (1987). 
the orientation of the line is supported by the travel time deduced from a multiple reflection recorded at profile $\mathrm{km} \mathrm{120}$. When a correlation of the ice-bottom reflector is carried out, the extraction of travel times at shot point $t_{0}$ is possible. With $t_{0}$ and the ice thickness it is easy to obtain the amount of water beneath the ice shelf from the existing travel times of the sea-bottom reflector, taking a sea-water velocity of $1480 \mathrm{~m} / \mathrm{s}$. The final results are shown in Table I. Estimated errors include an uncertainty of $\pm 5 \mathrm{~ms}$ for travel times and $\pm 50 \mathrm{~m} / \mathrm{s}$ for seismic velocities, giving overall errors of less than $20 \mathrm{~m}$ for depths of ice and the sea bottom.

\section{DISCUSSION AND CONCLUSION}

The ice depths revealed by seismic investigations can be compared with data from an aerogeophysical survey (Thyssen 1988, this volume) running parallel to the seismic profile and yielding altitudes of the ice surface. According to the buoyancy of the ice shelf, thicknesses can be derived from the height of the surface above sea-level, even if the uncertain density below the internal horizon causes some deviations. Errors in the measurement of seismic depths are almost equivalent to those obtained from considering hydrostatic equilibrium (Fig. 5).

The end of the seismic profile coincides with the location of a drill hole that reached the ice bottom at about $465 \pm 5 \mathrm{~m}$ depth, in good agreement with the seismic value of $447 \pm 20 \mathrm{~m}$. Although seismic reflections from the sea bottom are easy to obtain, errors in sea depth are strongly affected by uncertainties in the ice thickness. Summing up, it may be concluded that seismic investigations can be successful in obtaining ice-bottom depths, even in places where electromagnetic techniques fail, provided that distances between shot points are sufficiently small. There are two more bands of thin ice in the west of FRIS, stretching back from the ice front to near the grounding line (Crabtree and Doake 1986; Thyssen 1988, this volume). It would be advisable to check these anomalies, which appear to be up to $300 \mathrm{~m}$ thinner than the surrounding areas, by more reflection-seismic measurements on a cross-profile.

\section{ACKNOWLEDGEMENTS}

This work has been supported by the Bundesministerium für Forschung und Technologie, the Deutsche Forschungsgemeinschaft and the Ministerium für Wissenschaft und Forschung Nordrhein-Westfalen.

\section{REFERENCES}

Crabtree, R.D., and C.S.M. Doake. 1986. Radio-echo investigations of Ronne Ice Shelf. Ann. Glaciol., 8, 37-41.

Engelhardt, H., and J. Determann. 1987. Borehole evidence for a thick layer of basal ice in the central Ronne Ice Shelf. Nature, 327(6120), 318-319.

Garotta, D., and D. Michon. 1967. Continuous analysis of the velocity function and the move out corrections. Geophys. Prospect., 15, 584-597.

Herrod, L.D.B., and S.W. Garrett. 1986. Geophysical fieldwork on the Ronne Ice Shelf, Antarctica. First Break, 4(1), 9-14.

Kohnen, H. 1982. Glaciological investigations in the frontal zone of the Filchner and Ronne ice shelves. Ann. Glaciol., 3, 160-165.

Robin, G. de Q., C.S.M. Doake, H. Kohnen, R.D. Crabtree, S.R. Jordan, and D. Möller. 1983. Regime of the Filchner-Ronne ice shelves, Antarctica. Nature, 302(5909), 582-586.

Thyssen, F. 1985. First results from Polar-2-measurements on the Filchner and Ekström ice shelves. In Kohnen, H. comp. Filchner-Ronne-Ice-Shelf-Programme. Report No. 2. Bremerhaven, Alfred-Wegener-Institute for Polar Research, 131-132.

Thyssen, F. 1986. The central part of the Filchner/Ronne Ice Shelf. In Kohnen, H., comp. Filchner-Ronne-IceShelf-Programme. Report No. 3. Bremerhaven, AlfredWegener-Institute for Polar and Marine Research, 81-83.

Thyssen, F. 1988. Special aspects of the central part of Filchner-Ronne Ice Shelf, Antarctica. Ann. Glaciol., 11, 173-179. 